\title{
The Strengthening of Geological Infrastructure, Research and Data Acquisition - Using Gis in Ivory Coast Gold Mines
}

\author{
Kouame Joseph Arthur Kouame , Fuxing Jiang, Yu Feng and Sitao Zhu \\ School of Civil and Environmental Engineering, University of Science and Technology Beijing, Beijing, China
}

\begin{abstract}
The artisanal gold mining in Ivory Coast has become a key problem in the mining sector. A diverse group of people in Ivory Coast, including the young and the old, are all engaged in these activities that are reportedly better than agricultural inputs. . However, it is still a high-risk activity that leads to pollution, environmental degradation and the loss of human life. About ten people die each year in the gold mines. This paper focuses on gold mine safety by using the Geographic Information System (GIS) as a major solution to solve the artisanal gold mines problem, and also seeks to promote the mining industry in Ivory Coast.
\end{abstract}

\section{Introduction}

\subsection{Definition of artisanal mining}

The term Artisanal and Small-scale mining broadly refers to a mining practiced by individuals, groups, or communities, often occurring informally in developing nations. A common definition of this sector has not been adopted yet as a legal status, and local definitions vary from country to country. Due to this reason, it is difficult to estimate the extent of artisanal mining in developing contexts due to the lack of a common definition, its use of seasonal workers, and the lack of official statistics [1] (Hilson, G., 2002).

Artisanal mining is a thorny issue for both governments and large-scale mining areas in developing countries due to the various associated benefits and risks. In the last ten to fifteen years, the introduction of technology that has made this mining process more efficient. The problem however is that artisanal mining is not all that risk free. This paper focuses on artisanal mining in the Ivory Coast.

\subsection{Artisanal mining in the Ivory Coast}

Ivory Coast in the western part of Africa has a high fertility rate that is expected to reach nearly $80 \%$ in 2018 . The increasing poverty rate of the population is mainly due to the presence of the youth, men, and women in the artisanal gold mines. Many children who became orphans during the rebellion in 2002 and the post electoral crisis; view working in the artisanal gold mines as the perfect job to provide for their daily bread and to support their relatives. A majority of the breadwinners of a family in
Africa are children. ([2], [3]) (African Economic Outlook, 2013 and Carisch, 2012). The country has a large portion of the Birimian geological formations that make West Africa a mining region par excellence. In the case of the Ivory Coast, the issue of mining became rampant during the period of turmoil between 2003 and 2011, mainly due to the absence of a state authority, particularly in the north that was occupied by rebels at the time. Many efforts have been made to the promotion and transfer of artisanal mining in the so-called "small scale" mine by West African states, through projects and multi-sectorial funding programs that aim at optimizing national investment and promoting socio-economic welfare through the fight against poverty, assistance in communities settlement, protection of the environment, and quality of life improvement, among others [4] (Sogal, 2012).

Recent research has shown that artisanal miners have increased in number, and artisanal mining activities have become a privileged destination for local people and foreigners in the western part of Africa such as Ivory Coast, Guinea, Mali, and Ghana. This is mainly due to their changed livelihood standards, as a result of this activity ([5]-[7]) (Hilson et al., 2013, Bryceson and Jonsson 2009, Nyame et al, 2010).

According to SODEMI, the unique national company in Ivory Coast 24 out of 31 regions in the country are being illegally exploited by more than 500,000 miners which are mostly foreigners and indigenous people [8] (Assie, 2009). But we cannot determine the real number of the people who venture into illegal gold mine activities in the country, due to the fact that local people sometimes connive with foreigners for these activities. Despite the current government of Ivory Coast taking a decision to close several illegal mines around some cities like Ity, 
Djekenou Zanzan region, Zouan-Hounien, and other regions, illegal miners always back to the gold exploitation on the same sites after few months ([9]-[11] (Randgold Resources Ltd., 2012, Economie, 2015, AZUBUIKE.OKEH, 2014).

The vast majority of artisanal mining is illegal. Miners usually have to apply for a license to mine from the local authorities before they start digging, but the local industry estimates that $95 \%$ of all the artisanal mining goes ahead without such regulations. Regulation, rather than banning artisanal mining altogether is the only sustainable solution.

In the 1990's, the liberalization of the gold mining industry meant a downward shift in terms of environmental, human rights as well as transparency standards in many of the West African states. This is the case because the goal at the time was to lure foreign investors. However, governments at present need to come together and to harmonize the standards upwards. There has been some progress in this regard, due to the efforts of regional bodies such $\mathrm{s}$ the Economic Community of West African States (ECOWAS), which is working on a new mining code to apply to all its members. It is expected that this law would be deliberated on and passed in the following years, after heads of state within the region passed a directive on high level commitment to mining. With artisanal mining growing steadily and industrial scale mining set to significantly increase between now and 2020, networks and industries need to work hard and keep tabs on the industry at all levels.

However, Ivory Coast is now becoming a trustful country in the world after 10 years of political unrest. The current government attaches a great importance to the safety of persons and property. The poverty rate averages slightly, and the country's GDP grew from 7\% in 2011 to $13 \%$ in 2013 . The country can borrow funds from the World Bank and also from other financial institutions such as the Inter-American Development Bank (IDB) to acquire new technologies and invest fully in the mining sector. This is the case because recent research has shown satisfactory results that have discovered a huge mining potential in many parts of the national territory. (Fig. 1).

In the gold mine or coal mine production process, safety is a very important part of the disaster prevention in terms of mine gas disasters, coal dust hazards, and fire hazards. Unfortunately, Ivory Coast at present has a lot of artisanal gold mines such that the safety information management level is still relatively backward and has not completely desorbed from the traditional manual operation. The presence of low work efficiency, staff duplication, difficult data found in long series of problems in the information transfer cycle, and untimely safety information and accident reporting treatment, leads to vicious consequences of property damage and casualties. Therefore, carrying out a research of mining safety information on the safety management of gold production in Ivory Coast is of important significance.

The geospatial information technologies (GIS) and geospatial integrated information technology (IT) are increasingly used in the field of the mining industry. This new technology continues to improve the views of all their utilities in management of mining resources, planning and good management infrastructure in localisation and assessments of mining sites. These modern advanced technologies are also important in the health field of education and administration.

The majority of the mining deposit in Ivory Coast is mainly found in a gold mine that is located in the northern, western, central and eastern part of the country, as the most explored targets for gold deposits. The gold deposit in Ivory Coast has been previously interpreted since the independence, but today young gold has been discovered in Angovia and bonikro. Today several foreign mining companies are heading to the country for further deep explorations and exploitations for those already had the exploration permits. This is due to the fact that the government of the Ivory Coast has begun to take an interest in the mining sector in order to diversify its economy that is primarily based on agriculture. However some mining investors have met with problems such conflict over land and insecurity due to the presence of thousands of artisanal gold miners. For this reason, this paper is mainly focussed on offering GIS as a tool to establish a real predictive model for mapping gold mineralization in all the regions in the country to preventing such outcomes.

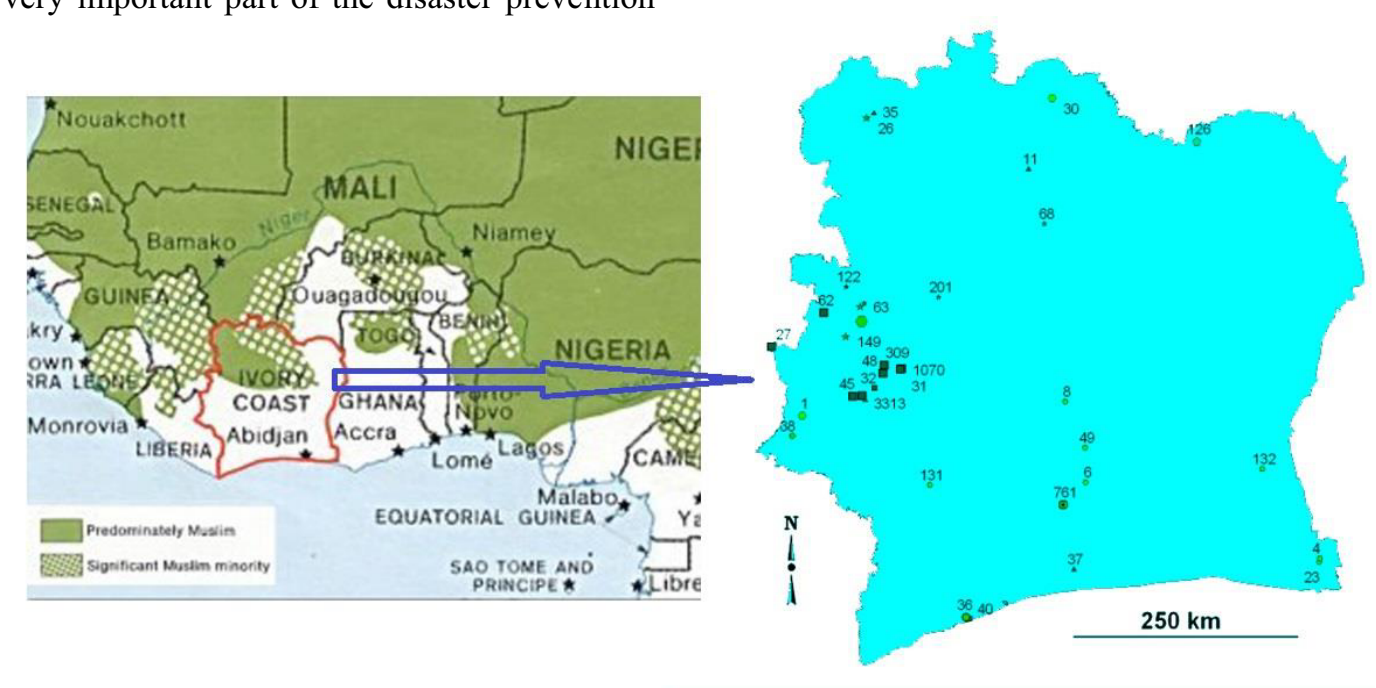

Figure 1. Legend and ore deposit name in Ivory Coast 


\section{System design}

\subsection{Functions of GIS system}

The geographic information system (GIS) will exist to elaborate the map information management and to deal with monitoring information system management in Ivory Coast (Fig. 2).

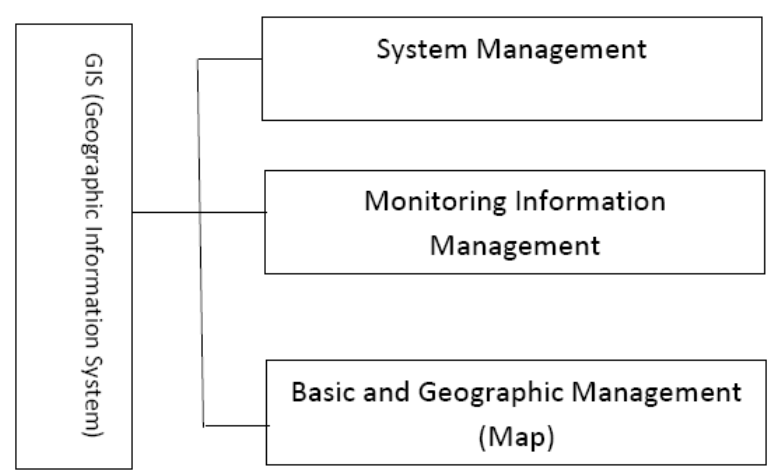

Figure 2. System functional

\subsection{Elaboration of the map information management}

GIS-based graphics leads to achieve the map to zoom, pan, layer control and other editing functions. At the same time, it realizes maps and attributes peer review. Ivory Coast is today a privilege destination for artisanal miners. Thousands foreigners and citizens are involved in artisanal and small-scale mining (ASM) in Ivory Coast due to the high rate of poverty and unemployment, which are the direct consequences of the political unrest from 1999 to 2011 [12] (UN, 2014).

The adoption of the new technology will play a major role in the Ivory Coast mining industry, by elaborating maps which will locate all the mining sites of the national territory first, and then identify all the artisans involved in the artisanal gold mining sector who illegally exploit the natural resources of countries. The Government of Ivory Coast will as such be able to control the quasi totality of the mining sector and take necessary steps towards better management of natural resources. This is the case because the lower system operating environment requirements provides a friendly user interface, which is easy for nonGIS personnel to operate the application.

\subsection{Monitoring information system management}

The real development of the mining sector in the Ivory Coast necessitates the understanding of knowledge of the mineral potential of each region and locality of the country. The new advanced technologies will be useful in obtaining accurate information on natural resources in Ivory Coast. Data based information will be acquired, processed and analyzed according to the geographical information of each locality and area of the Ivory Coast. Due to the dynamics of new advanced techniques and also their capacity expansion, the advanced technologies can collect geological data, resulting in many problems such as soil degradation and restoration of the environment being resolved. Land used jointly by mining, communities and epidemiology will be evaluated. Additionally, the deaths and flooding of the mine site will also be attenuated. As a result, the possibility to record all mineral production from the Ivory Coast and provide transparent and based information to the mining administration through the use of new technologies will be a great asset to the country's economy. Ivory Coast will experience a rapid economic development, epidemiologically secures evaluation, and disaster recovery. This is due the fact that the mine safety monitoring system with real-time data exchange, data exchange files for safety monitoring system, in accordance with a given data format specification, development of the data read and display algorithm, can read data files in real-time monitoring systems, the underground monitoring basic information and its operational status information about the device is displayed on the map.

\section{The main function}

The GIS system will be important in the mining industry in Ivory Coast in the following way:

(1) The introduction of the GIS in Ivory Coast mining operation will lead to the safety of local people and miners due to the medical system management in the operational mining areas. Numerous diseases such as lungs, heart and skin diseases, and also the spreading of HIV / AIDS are very often recorded on mining sites.

It is clear that GIS is now an important element in the medical service. The medical sector actors use GIS to invest in the geographical effects on humans. The Ivory Coast must be endowed with GIS for environmental preservation. Thus the risk of epidemic and infectious diseases proliferation will be greatly reduced on mining sites, and the local population will be free from diseases. In our advanced case, the use of GIS is essential because it can detect danger on future mining operation sites. The government of Ivory Coast will certainly invest huge funds for the acquisition of new geologic technologies, but the rewarding of that will greatly benefit the reduction of the WHO liabilities, which include the construction of hospitals and treatment of those suffering from HIV / AIDS and, tuberculosis. The proceeds will be used to solve some immediate problems of the population such as unemployment, securities, and poverty.

(2) GIS is a system which has good interactive capabilities, automatic connection and a two-way electronic map and database queries, and functions according to the need for thematic map output. Compared to the previous cut graphics and data established mutual monitoring software, this system has successfully realized the data and graphics correspondence and sync output. Many mining sites in Ivory Coast remain undiscovered or undeveloped, and some exploited sites even have often been abandoned by their operators due to the political unrest or land conflict between the mining companies and local people. The existence of many undeveloped mining sites is thus due to the lack of the high technology in the 
mining sector in Ivory Coast. Some of the major strengths of a Geographic Information System (GIS) include its ability to plan a reclamation activity. Additionally, potential problems in operation can be remotely monitored and diagnosed by experts, who can propose effective solutions and provide technical support directly through online consultation

The active use of GIS applications will lead to the restoration of most of the abandoned mining sites in Ivory Coast. The minerals (gold, diamond, iron..) which are currently exploited by illegal miners in the northern, western, central and even in the southern part of the country can be controlled by the government and attributed to some reliable foreign investors such as Amara mining, the British mining company; which is expected to run the biggest gold mine deposit in 2017. The mining industry will be the second largest sector of the country's economy beside cocoa ([13-15]) (United Nations. Resolution 1528 (2011); United Nations. Resolution 2045 (2011); Ogwang Tom, 2011).

\section{Conclusions}

GIS-based integrated safety management is a system that holds a great and high level of visual, interactive and good man-machine interface coordination. This will assist in creating a real stable and fast response, with a strong security comprehension due to the smart work of GIS and its applications. The system plays an impressive role in safety management, as well as controlling and reducing the mine disasters during the operation. A good use of GIS leads to the development of the mining sector and enhances better management levels. Besides the technical support of GIS system in the advance sustainable development of gold mine production safety, GIS will play an increasingly large role in the mining industry in Ivory Coast. As such, the development of GIS - based graphic safety technology with an integrated visual information management system, which aims at enhancing the level of mine safety management in the Ivory Coast, is essential.

\section{References}

1. G. Hilson, Small-scale mining and its socioeconomic impact in developing countries, In Natural Resources Forum, Blackwell Publishing Ltd. 26(1): 3-13 (February 2002)

2. African Economic Outlook, Promoting youth employment in Africa, Why an African economic outlook on youth employment, (2013)

3. E. Carisch, Conflict gold to criminal gold: The new face of artisanal gold mining in Congo, South Africa: Southern Africa Resource Watch, (2012).
4. S.G. Sogah, The effects of differences in agroecosystems on the diversity and distribution of avifauna in selected areas in the Eastern Region of Ghana, Doctoral dissertation, (2012).

5. G. Hilson and C. Garforth, Everyone now is concentrating on the mining: drivers and implications of rural economic transition in the eastern region of Ghana, Journal of Development Studies, 49(3):348364 (2013)

6. J.B. Jønsson and D.F. Bryceson, Rushing for Gold: Mobility and Small-Scale Mining in East Africa. Development and Change, 40(2): 249-279 (2009)

7. F.K. Nyame and J. Blocher, Influence of land tenure practices on artisanal mining activity in Ghana, Resources Policy, 35(1), 47-53 (2010)

8. K.E. Assie, Lode gold mineralization in the Paleoproterozoic (Birimian) volco-sedimentary sequence of Afema gold district, southeastern Cote d'Ivoire, $\mathrm{PhD}$ thesis, Technical University of Clausthal, Germany, (2009)

9. Randgold resources Ltd., 2011 annual report: London, United Kingdom, Randgold resources Ltd., p. 185, (2012)

10. Economie. (December 21, 2015). Centre-Ouest ivoirien: La mine d'or de Gamina exploitée illégalement un mois après sa fermeture (REPORTAGE). Retrieved Decembre 24, 2015, from Abidjan.net: http://news.abidjan.net/h/576676.html

11. AZUBUIKE.OKEH. (October 23, 2014). Cote d'Ivoire closes 150 illegal gold mines. Retrieved November 12, 2014, from NEWS AGENCY OF NIFERIA: http://nannewsnigeria.com/cote$\mathrm{d} \%$ E2\%80\%99ivoire-closes-150-illegal-gold-mines

12. United Nations Security Council, 2011a, Letter dated 17 October 2011 from the Chair of the Security Council Committee established pursuant to resolution 1572 (2004) concerning Côte d'Ivoire addressed to the President of the Security Council: United Nations Security Council report S/2011/642, p. 34

13. UN Security Council Security Council members unanimously adopt resolution 2153 (2014), 2014 Reed, Jared, 29.04.2014 http://www.dw.de/un-liftsdiamond-export-embargo-for-ivory-coast/a17601628

14. United Nations Security Council, 2011b, Letter dated 20 April 2011 from the Chair of the Security Council Committee established pursuant to resolution 1572 (2004) concerning Côte d'Ivoire addressed to the President of the Security Council: United Nations Security Council report S/2011/272, p. 80

15. T. Ogwang, The root causes of the conflict in Ivory Coast, Backgrounder, (5):1, (2011) 